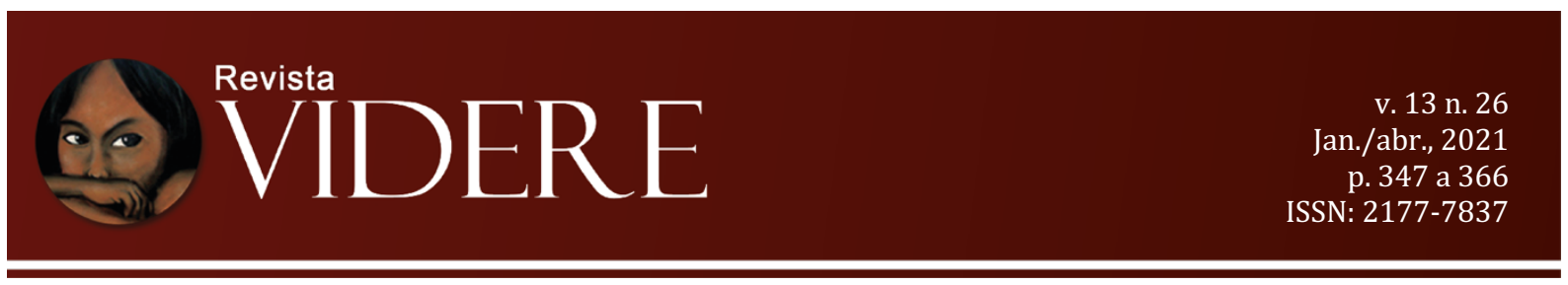

\title{
A APLICAÇÃO DOS PRINCÍPIOS ORIENTADORES SOBRE EMPRESAS E DIREITOS HUMANOS DA ONU E CONFLITOS SOCIOAMBIENTAIS NO ÂMBITO DA MINERAÇÃO
}

\author{
APPLICATION OF THE GUIDING PRINCIPLES ON UN COMPANIES AND HUMAN \\ RIGHTS AND SOCIO-ENVIRONMENTAL CONFLICTS IN THE MINING SCOPE
}

\begin{abstract}
APPLICATION DES PRINCIPES DIRECTEURS SUR LES ENTREPRISES DES NATIONS UNIES ET LES DROITS DE L'HOMME ET LES CONFLITS SOCIOENVIRONNEMENTAUX DANS LE CHAMP D'APPLICATION MINIER
\end{abstract}

\author{
Eliane Cristina Pinto Moreira \\ Pós-doutora pela Universidade Federal de \\ Santa Catarina \\ moreiraeliane@hotmail.com \\ Orcid ID: https://orcid.org/0000-0001-9085-041X \\ Leandro Barbalho Conde \\ Mestre pela Universidade Federal do Pará \\ leandrobconde@gmail.com \\ Orcid ID: https://orcid.org/0000-0002-0718-2594
}

Resumo: Este artigo propõe uma investigação sobre o Caso Mineração Onça Puma x Povo Xikrin do Cateté, sob a perspectiva dos Princípios Orientadores sobre Empresas e Direitos Humanos, os quais foram aprovados pelo Conselho de Direitos Humanos da Organização das Nações Unidas no ano de 2011 e estão estabelecidos no Brasil pelo Decreto ${ }^{\circ}$ 9.571/2018. De início, o artigo discorre sobre o Caso envolvendo danos ambientais na terra indígena do Povo Xikrin do Cateté que envolveu o Projeto de Mineração Onça Puma. Apesar de ainda não estar sentenciado no juízo de origem já tramitou por todas as instâncias do Poder Judiciário nacional. Em seguida, é demonstrado que o próprio Poder Público figura como vetor do conflito, inclusive propondo ações judiciais pretendendo que o empreendimento retorne às atividades em face de suspensão por determinação judicial. Por fim, é exposto breve histórico sobre o tema "empresas e direitos humanos" junto a Organização das Nações Unidas, destacando os Princípios Orientadores sobre Empresas e Direitos Humanos e o relatório direcionado ao Brasil com diversas recomendações, preparado pelo Grupo de Trabalho que atua na temática. Ao final, se concluí que, apesar de o Poder Judiciário brasileiro ter perdido a oportunidade de aplicar ao Caso os Princípios Orientadores já estabelecidos no Brasil, o Caso, que atualmente está suspenso em razão de um acordo entre as partes, ainda é uma oportunidade de introduzir na 
jurisprudência pátria os mecanismos internacionais de proteção de direitos humanos objeto de análise, a fim de proteger de direitos socioambientais violados por empresas transnacionais.

Palavras-chave: Direitos Socioambientais; Jurisprudência; Princípios Orientadores sobre Empresas e Direitos Humanos.

Abstract: This article proposes an investigation into the Onça Puma Mining Case $\mathrm{x}$ Xikrin People of Cateté, from the perspective of the Guiding Principles on Business and Human Rights, which were approved by the Human Rights Council of the United Nations in 2011 and are established in Brazil by Decree $n^{\circ} 9.571$ / 2018. At first, the article discusses the Case involving environmental damage in the indigenous land of the Xikrin people of Catete that involved the Onça Puma Mining Project. Although not yet sentenced in the court of origin, it has already been processed by all instances of the national Judiciary. Then, it is demonstrated that the Public Power itself appears as a vector of the conflict, including proposing lawsuits intending that the enterprise returns to its activities in the face of suspension by judicial determination. Finally, a brief history on the topic "business and human rights" is presented to the United Nations, highlighting the Guiding Principles on Business and Human Rights and the report addressed to Brazil with several recommendations, prepared by the Working Group that works on thematic. In the end, it was concluded that, although the Brazilian Judiciary has lost the opportunity to apply the Guiding Principles already established in Brazil to the Case, the Case, which is currently suspended due to an agreement between the parties, is still an opportunity to to introduce in the homeland jurisprudence the international mechanisms of protection of human rights object of analysis, in order to protect of socio-environmental rights violated by transnational companies.

Keywords: Social and Environmental Rights; Jurisprudence; United Guiding Principles on Business and Human Rights.

Résumé: Cet article propose une enquête sur l'affaire minière Onça Puma x le peuple Xikrin de Cateté, du point de vue des Principes directeurs relatifs aux entreprises et aux droits de l'homme, qui ont été approuvés par le Conseil des droits de l'homme des Nations Unies en 2011 et sont établis au Brésil par le décret $\mathrm{n}{ }^{\circ} 9.571 / 2018$. Au début, l'article traite de l'affaire des dommages environnementaux sur les terres indigènes du peuple Xikrin de Cateté, qui impliquait le projet minier Onça Puma. Bien qu'elle n'ait pas encore été condamnée par le tribunal d'origine, elle a déjà été traitée par toutes les instances du pouvoir judiciaire national. Ensuite, il est démontré que la puissance publique elle-même apparaît comme un vecteur du conflit, proposant notamment des poursuites judiciaires visant à ce que l'entreprise reprenne ses activités face à une suspension par décision judiciaire. Enfin, un bref historique sur le thème «entreprises et droits de l'homme» est présenté aux Nations Unies, mettant en évidence les Principes directeurs relatifs aux entreprises et aux droits de l'homme et le rapport adressé au Brésil avec plusieurs recommandations, préparé par le Groupe de travail qui travaille sur des thèmes. En fin de compte, il a été conclu que, bien que le pouvoir judiciaire brésilien ait perdu l'occasion d'appliquer les principes directeurs déjà établis au Brésil à l'affaire, l'affaire, qui est actuellement suspendue en raison d'un accord entre les parties, est toujours une occasion de d'introduire dans la jurisprudence nationale les mécanismes internationaux de protection des droits de l'homme objet d'analyse, afin de se protéger des droits socio-environnementaux violés par les sociétés transnationales.

Mots clés: Droits socio-environnementaux; Jurisprudence; Principes directeurs relatifs aux entreprises et aux droits de l'homme. 


\section{Introdução}

O presente artigo propõe uma investigação sobre o Caso envolvendo o projeto de Mineração Onça Puma e Povo Xikrin do Cateté, sob a perspectiva dos Princípios Orientadores sobre Empresas e Direitos Humanos, os quais foram aprovados pelo Conselho de Direitos Humanos da Organização das Nações Unidas no ano de 2011 e estão estabelecidos no Brasil pelo Decreto ${ }^{\circ} 9.571$, de 21 de novembro de 2018.

O objetivo do trabalho é verificar se o referido caso é uma oportunidade do Poder Judiciário brasileiro efetivar a aplicação dos Princípios Orientadores sobre Empresas e Direitos Humanos, os quais foram aprovados pelo Conselho de Direitos Humanos da Organização das Nações Unidas no ano de 2011 e estão estabelecidos no Brasil pelo Decreto ${ }^{\circ} 9.571$, de 21 de novembro de 2018 .

Na primeira sessão, a pesquisa apresenta o caso em sí e seu desenrolar perante o Poder Judiciário, considerando que apesar de ainda não estar sentenciado no juízo de origem já tramitou por todas as instâncias do Poder Judiciário nacional.

A partir deste ângulo, é feita a análise das principais ações judicias que envolvem o conflito socioambiental, em que figuram, entre outras partes, o Ministério Público Federal, a Mineradora Onça Puma e o Povo Xikrin do Cateté.

Em seguida, é demonstrado que o próprio Poder Público figura como vetor do conflito, inclusive propondo ações judiciais pretendendo que o empreendimento retorne as atividades em face de suspensão por determinação judicial.

$\mathrm{Na}$ última sessão, é exposto breve histórico sobre o tema "Empresas e Direitos Humanos" e seu tratamento perante a Organização das Nações Unidas (ONU), destacando os Princípios Orientadores sobre Empresas e Direitos Humanos e o relatório direcionado ao Brasil com diversas recomendações, preparado pelo do Grupo de Trabalho que atua na temática.

Importante destacar que, em que pese haver críticas quanto aos Princípios Orientadores sobre Empresas e Direitos Humanos, no que tange a influência política e econômica das empresas transnacionais na elaboração do referido documento, este trabalho não adentra em tal discussão, apenas expõe o histórico sobre a formação do documento e sua aplicabilidade e sua potencial utilização pelo Sistema de Justiça. 
Destaca-se ainda que o presente artigo não analisa os artigos dispostos nos Princípios Orientadores sobre Empresas e Direitos Humanos. Para os fins deste estudo, são analisadas somente as características de cada um dos três pilares em que o documento é assentado.

Ao final, se concluí que, apesar de o Poder Judiciário brasileiro não ter aplicado estes princípios, o que pode ser visto como uma perda de oportunidade para sua consolidação no Brasil , o Caso, que atualmente está suspenso em razão de um acordo entre as partes, ainda é uma oportunidade de introduzir na jurisprudência pátria os mecanismos internacionais de proteção de direitos humanos objeto de análise, a fim de para proteger de direitos socioambientais violados por empresas transnacionais.

Como critério para a conclusão do trabalho é apontado caso semelhante julgado pela Corte Interamericana de Direitos Humanos, em 2015 que resultou na condenação do Estado do Suriname, ressaltando a importância da observância dos Princípios Orientadores sobre Empresas e Direitos Humanos, no caso que envolveu conflito socioambiental que teve como vetor o Poder Público como principal causador de danos provocados a povos indígenas decorrente de atividade minerária de empresa transnacional, por violação de direitos socioambientais.

\section{Conflito socioambiental envolvendo a Mineradora Onça Puma e Povo Xikrin do Cateté.}

O Povo Xikrin do Cateté, que faz parte do grupo Kayapó, se autodenominam mebengokré, que significa "gente do buraco d'água" ou "gente da água grande", em referência aos rios Tocantins e Araguaia (MPF. Ação Civil Pública nº 0002383-85.2012.4.01.3905, 2012).

Atualmente, os Xikrin são divididos em três aldeias, Pukatingró, Djudjekô e Oodja, todas localizadas as margens do Rio Cateté (MPF. Ação Civil Pública no 000238385.2012.4.01.3905, 2012), que é localizado na bacia Araguaia-Tocantins e recebe águas de igarapés provenientes da Serra do Puma (MINERAÇÃO ONÇA PUMA. Relatório de Impacto Ambiental. Mineração Onça Puma, 2004). Daí decorre uma importante relação entre este povo indígena e o Rio Cateté.

A Terra Indígena (TI) Xikrin do Rio Cateté que, após a demarcação, foi homologada no Decreto Presidencial no 384, de 1991, é sobreposta, na parte da Serra do Puma, por um dos títulos minerários registrados no Departamento Nacional de Produção Mineral (DNPM), identificados pelos processos $\mathrm{n}^{\mathrm{o}} 811.015 / 73,811.016 / 73,814.621 / 73$ e 814.622/73 (MINERAÇÃO ONÇA PUMA. Relatório de Impacto Ambiental. Mineração Onça Puma, 2004). 
O Estado do Pará, em agosto de 2004, concedeu a Mineração Onça Puma Ltda (MOP), subsidiária da empresa Vale S/A, licença prévia (LP) para o empreendimento, que é estabelecido em área contígua a TI dos Xikrins e tem como principal objetivo "produzir ferroníquel através de operações convencionais de mineração e processamento do minério em uma usina metalúrgica”. (MPF. Ação Civil Pública nº 0002383-85.2012.4.01.3905, 2012).

Em abril de 2005, o Estado do Pará, emitiu a licença de instalação (LI) do empreendimento e, finalmente, em agosto de 2008, a licença de operação (LO) das atividades de lavra, que foi renovada em abril de 2010, quando foi emitida, ainda, a licença de operação da atividade de beneficiamento de minério (MPF. Ação Civil Pública $\mathrm{n}^{\circ}$ 000238385.2012.4.01.3905, 2012).

O empreendimento foi inaugurado em maio de 2011 (MPF. Ação Civil Pública no 0002383-85.2012.4.01.3905, 2012).

Nessa esteira, como os documentos que compunham o Procedimento Administrativo $\mathrm{n}^{\mathrm{o}}$ 1.23.001.000304/2005-74 aberto para acompanhar o Caso atestavam que o empreendimento minerário iniciou suas atividades sem apresentar a conclusão do Plano Básico Ambiental (PBA) que deveria indicar as medidas preventivas, mitigadoras e compensatórias aos impactos que ocorreriam na Terras Indígenas, o Ministério Público Federal (MPF), através da Portaria $\mathrm{n}^{\mathrm{o}} 42$, de 18 de julho de 2011, instaurou o Inquérito Civil Público (ICP) para investigar a questão. (MPF. Ação Civil Pública nº 0002383-85.2012.4.01.3905, 2012).

Em seguida, após concluir que a Vale S/A, a MOP, o Estado do Pará e a Fundação Nacional do Índio (FUNAI) causaram danos ao Povo Xikrin e Kaiapó, o MPF ajuizou Ação Civil Pública (ACP), perante a Seção Judiciária de Redenção/PA, onde tramita sob nº 000238385.2012.4.01.3900, resultando na judicialização do Caso objeto de análise nesta pesquisa. ${ }^{1}$

$\mathrm{Na}$ ACP, o MPF pleiteia, liminarmente, a suspensão das atividades minerárias praticadas próximas a terras indígenas e um depósito mensal pelo MOP de R $\$ 1.000 .000,00$ (um milhão de reais) a ser revertido em favor das comunidades indígenas; no mérito, a condenação da Vale S/A, da MOP, do Estado do Pará e a da Fundação Nacional do Índio (FUNAI), por danos materiais e morais. (MPF. Ação Civil Pública no 000238385.2012.4.01.3905, 2012).

\footnotetext{
${ }^{1}$ Apesar de os danos socioambientais gerarem prejuízo ao Povo Kaiapó, optamos neste pesquisa por estabelecer corte metodológico sobre o Povo Xikrin, considerando as especificidades que cada povo possui e também as discussões judiciais que muito se centraram sobre os danos sofridos pelo povo Xikrin.
} 
O juízo de Redenção/PA deferiu parcialmente a liminar para obrigar a MOP a depositar quantia mensal bem menor que a pleiteada, levando as associações indígenas que se habilitaram nos autos e o MPF a agravar da decisão (STF. Suspensão de Liminar nº 933, 2015).

O Tribunal Regional Federal da $1^{\mathrm{a}}$ Região (TRF 1), no agravo de instrumento de $\mathrm{n}^{\mathrm{o}}$ 0042106-84.2015.4.01.0000, por decisão monocrática do Relator do caso, Desembargador Souza Prudente, deferiu a antecipação de tutela recursal postulada pelo MPF para determinar, tanto a suspensão das atividades de mineração, como o depósito mensal de R $\$ 1.000 .000,00$, além de impor também, multa diária para a hipótese de descumprimento da decisão, no valor de R \$ 10.000,00 (STF. Suspensão de Liminar nº 933, 2015).

Nessa medida, a Vale S/A, ante a "ausência de recurso cabível” impetrou, junto a Presidência daquele do TRF $1^{\mathrm{a}}$, mandado de segurança (MS) contra a decisão proferida pelo relator do feito acima mencionado, conseguindo a suspensão liminar do julgado (STF. Suspensão de Liminar n ${ }^{\circ}$ 933, 2015).

Ante a decisão da Presidência da Corte federal regional, os desdobramentos do conflito saltaram para as instancias extraordinárias do Poder Judiciário.

O MPF propôs a Suspensão de Segurança no 2.796 para o Presidente do Supremo Tribunal de Justiça, que sustou a liminar deferida na presidência do TRF 1 em sede de MS, restabelecendo, assim, a condenação imposta na decisão da $5^{\text {a }}$ Turma do mesmo Tribunal, em sede de agravo de instrumento (STF. Suspensão de Liminar nº 933, 2015).

Em seguida, a Vale e o Estado do Pará, recorreram do julgado e obtiveram, a reconsideração da decisão anterior para garantir que o depósito imposto na ACP fosse realizado em conta do juízo de origem bloqueada, ou seja, não passível de levantamento imediato pelas associações indígenas (STF. Suspensão de Liminar $n^{\circ}$ 933, 2015).

Ao chegar no Supremo Tribunal Federal (STF), o Caso de voto-vista do Ministro do STF, Luís Roberto Barroso, que assim narra o tramite processual na mais alta Corte:

11. (...) o Estado do Pará ajuizou a presente suspensão de liminar perante o Supremo Tribunal Federal, contra aquela primeira decisão do TRF da $1^{\mathrm{a}}$ Região, que havia deferido a antecipação de tutela recursal. Em 11.12.2015, o Min. Ricardo Lewandowski, então Presidente desta Corte, deferiu parcialmente o pedido pleiteado pelo Estado do Pará na presente suspensão de liminar para permitir as atividades de mineração, determinando, apenas, que as medidas compensatórias previstas no licenciamento ambiental fossem cumpridas em até 120 dias, sob pena de depósito mensal de R $\$ 1.000 .0000,00$, por aldeia. Em última análise, portanto, suspendeu-se o pagamento da indenização mensal pelo prazo de 120 (cento e vinte) dias. 
12. Após a decisão monocrática do Ministro Lewandowski, o Presidente do STJ encaminhou a SS n 2.796 ao Supremo Tribunal Federal - reautuada como Suspensão de Segurança $n^{\circ} 5.115$-, em razão de ter se reconhecido a natureza constitucional da questão, o que, segundo o seu entendimento, encerraria a jurisdição do STJ. A SS 5.115 encontra-se conclusa aguardando o julgamento da presente ação.

13. Na presente suspensão de liminar, o agravo regimental interposto pelas associações indígenas alega, em síntese, os seguintes fundamentos para a reforma da decisão monocrática do Ministro Ricardo Lewandowski: (i) a utilização de duas medidas excepcionais pelo Estado do Pará para garantir a manutenção do empreendimento minerário ( $\mathrm{SS} \mathrm{n}^{\circ} 2796$ e SL 933); e (ii) grave lesão à saúde e à segurança das comunidades indígenas com a continuação da atividade minerária. $\mathrm{Na}$ mesma linha, o agravo regimental interposto pelo MPF também postula a reforma da decisão, restabelecendo-se os comandos determinados pelo TRF da $1^{\mathrm{a}}$ Região quanto à suspensão da atividade $\mathrm{e}$ o depósito mensal compensatório às comunidades indígenas, tendo como fundamento os graves danos causados pelo empreendimento ao meio ambiente e aos indígenas.

(...)”. (STF. Suspensão de Liminar nº 933, 2015).

O STF, por maioria, deu provimento aos agravos regimentais citados referido no votovista, para indeferir o pedido de suspensão de liminar e restabelecer a antecipação de tutela recursal deferida pelo Desembargador Relator do TRF 1, Souza Prudente, nos autos do Agravo de Instrumento ${ }^{o}$ 0042106-84.2015.4.01.0000, de 03 de agosto de 2015. ${ }^{2}$ (STF. Suspensão de Liminar $\left.n^{\circ} 933,2015\right)$.

O Agravo de Instrumento acima mencionado, que foi interposto pelo MPF, foi julgado no mérito pela $5^{\text {a }}$ Turma do TRF 1 , no dia 13 de setembro de 2017, reformando a parte a decisão monocrática do Desembargador Relator, para alterar o valor do depósito mensal as aldeias e manter a determinação de imediata paralisação das atividades minerárias da MOP. (MPF. Agravo de Instrumento $\mathrm{n}^{\mathrm{o}}$ 0042106-84.2015.4.01.0000, 2015).

Posteriormente, o Estado do Pará ingressou com nova Suspensão de Liminar (SL) perante o STF, que tramita sob $n^{\circ} 1226$, em face de nova decisão monocrática Desembargador Souza Prudente.

Nessa oportunidade, em 07 de junho de 2019, o Relator prevento, ao detectar que as atividades não foram suspensas, em descumprimento à decisão judicial, reiterou, nos autos do Agravo de Instrumento $\mathrm{n}^{\mathrm{o}}$ 1004428- 76.2019.4.01.0000, a decisão de mérito proferida no Agravo de Instrumento $n^{\circ}$ 0042106-84.2015.4.01.0000, mantendo a paralisação da mineradora,

\footnotetext{
${ }^{2} \mathrm{O}$ Ministros Ricardo Lewandowski (Relator) e Gilmar Mendes foram vencidos em face da divergência da inaugurada pelos Ministros Marco Aurélio, que relatou o acórdão do julgamento plenário presidido pela Ministra Carmem Lúcia, em 31.05.2017.
} 
e elevou a multa coercitiva já arbitrada nos aludidos autos para o valor de $\mathrm{R} \$ 200.000,00$ (duzentos mil reais) por dia de atraso. (STF. Suspensão de liminar $n^{\circ} 1226,2020$ ).

Na SL 1226 do Estado do Pará, argumenta que houve alteração nas circunstâncias de fato e de direito depois do julgamento da $\mathrm{SL} \mathrm{n}^{\circ}$ 933, o que justifica o novo pleito de retomada das atividades da empresa (STF. Suspensão de liminar nº 1226, 2020).

Segundo o Estado do Pará, o resultado das perícias realizadas perante o juízo de origem, aponta não existir responsabilidade da empresa Vale S.A por "eventual contaminação do Rio Cateté ou mesmo a suposta ocorrência de nascimentos de indígenas com má formação, apostas das liminares concedidas", pois, ainda segundo alegado, eventual contaminação no rio Cateté decorreria do garimpo ilegal presente na região, e não do empreendimento Onça Puma (STF. Suspensão de Liminar $\left.n^{\circ} 1226,2020\right)$.

Em decisão monocrática, o Ministro Presidente do STF, Dias Toffoli, deferiu o pedido de suspensão de liminar proposto pelo Estado do Pará para sustar os efeitos do acórdão proferido no Agravo de Instrumento $\mathrm{n}^{\mathrm{o}}$ 0042106-84.2015.4.01.0000 e da decisão prolatada no Agravo de Instrumento $n^{\circ}$ 1004428-76.2019.4.01.0000. (STF Suspensão de Liminar $n^{\circ}$ 1226, 2020).

Atualmente, todos os processos judiciais decorrentes da ACP movida pelo MPF na Seção Judiciária de Redenção/PA que envolvem o Caso se encontram suspensos por um ano, inclusive a própria $\mathrm{ACP}$, em razão de ter sido realizado entre MPF, Vale S/A, MOP e os povos indígenas Xikrin do Cateté e Kaiapó um "pré-acordo" judicial, em duas sessões nos dias 21 de outubro e 4 de novembro a fim de que as partes citadas "discutam o prosseguimento dos estudos sobre os impactos, com a participação de universidades ou institutos de pesquisa públicos". (MINISTÉRIO PÚBLICO FEDERAL, 2020).

Desse modo, como se vê, a discussão judicial envolvendo o conflito socioambiental entre a mineradora e a comunidade indígena já ter tramitado por todas as instâncias do Poder Judiciário brasileiro, nem uma das instâncias do Poder Judiciário fizeram referência aos Princípios Orientadores sobre Empresas e Direitos Humanos (Princípios Orientadores), que, desde 2011, foram aprovados pelo Conselho de Direitos Humanos da Organização das Nações Unidas (ONU), e que serão melhor analisados na última sessão deste trabalho. ${ }^{3}$

\section{As irregularidades do licenciamento ambiental estadual como vetor de danos socioambientais e de violação de direitos humanos}

\footnotetext{
${ }^{3}$ O Decreto ${ }^{\circ}$ 9.571, de 21 de novembro de 2018, estabelece as Diretrizes Nacionais sobre Empresas e Direitos
} Humanos. 
O Relatório de Impacto Ambiental (RIMA) apresentado pela Mineração Onça Puma ao órgão ambiental do Estado do Pará, amparado no respectivo Estudo de Impacto Ambiental (EIA), informa que o objetivo principal do empreendimento Projeto Onça Puma é "produzir ferro-níquel, através de operações convencionais de mineração e processamento do minério em uma usina metalúrgica". (MINERAÇÃO ONÇA PUMA. Relatório de Impacto Ambiental. Mineração Onça Puma, 2004).

Depois de relatar a metodologia de definição das áreas de influência do empreendimento e critérios de avaliação de impacto, o EIA do projeto apresenta "uma síntese do diagnóstico ambiental das áreas do Projeto, segundo cada um dos meios, físico, biológico e antrópico, ou socioeconômico". (MINERAÇÃO ONÇA PUMA. Relatório de Impacto Ambiental. Mineração Onça Puma, 2004).

Quanto ao diagnóstico do meio físico, no que tange aos recursos hídricos e qualidade da água, o RIMA aponta o Rio Cateté, na bacia do Araguaia-Tocantins, como um dos principais curso d'água da área do projeto e que como o rio que recebe águas de igarapés provenientes da Serra do Puma e da área da usina metalúrgica. (MINERAÇÃO ONÇA PUMA. Relatório de Impacto Ambiental. Mineração Onça Puma, 2004).

Em relação ao diagnóstico do meio antrópico (socioeconomia), no subitem 7.3.4, o RIMA revela que a população Kayapó, habitante da terra indígena do mesmo nome, T.I. Kayapó, e a população indígena Xikrin do rio Cateté, habitantes da T.I. Xikrin do Cateté, estão localizadas na área de entorno Projeto Onça Puma. (MINERAÇÃO ONÇA PUMA. Relatório de Impacto Ambiental. Mineração Onça Puma, 2004).

Diante dos diagnósticos relatados, no item 9, o documento apresenta "as ações, planos e programas que serão adotadas para o controle, minimização ou eliminação dos impactos prognosticados na avaliação de impactos, para as etapas de implantação, operação e fechamento do empreendimento". (MINERAÇÃO ONÇA PUMA. Relatório de Impacto Ambiental. Mineração Onça Puma, 2004).

Neste ponto, o RIMA informa que "o detalhamento destas as ações e programas será realizado na fase posterior do licenciamento ambiental".

$\mathrm{Na}$ "Análise Preliminar de Risco Ambiental", o RIMA identifica "alguns riscos, basicamente relacionados à estocagem de óleos combustíveis e carvão, além de riscos associados ao transporte de insumos". (MINERAÇÃO ONÇA PUMA. Relatório de Impacto Ambiental. Mineração Onça Puma, 2004).

Ao final, o RIMA, conclui, sob o ângulo da "viabilidade ambiental e custo/benefício", que: 
A avaliação de impactos indicou que os impactos negativos gerados pelo empreendimento, em suas três fases, encontram-se dentro da condição de significância desprezível a marginal, refletindo intensidade baixa a média. A avaliação dos demais impactos reais considerados em função das medidas mitigadoras previstas, indica que os impactos negativos reais são assimiláveis pelo ambiente e encontram-se dentro do permitido pelas leis e normas pertinentes.

Os impactos positivos reais apresentam-se, em sua maioria, significância relevante e estratégica e intensidade muito alta e alta, refletindo o potencial do empreendimento em promover importantes modificações favoráveis na sua área de influência, principalmente no meio socioeconômico.

O estudo ambiental também conclui que devem ser implantados programas de monitoramento para que se possa avaliar a eficiência das medidas de mitigação propostas e que o empreendedor possa atuar, de forma ativa, sempre que algum parâmetro medido esteja fora dos definidos pelas normas e legislações vigentes.

Dessa forma, os impactos ambientais negativos serão minimizados e controlados e os positivos serão maximizados, implicando em uma análise do custo/benefício ambiental do empreendimento como um todo, onde os benefícios são maiores que os custos ambientais para sua realização.

Dessa forma, como se verifica, o Estado do Pará, ao conceder as licenças ambientais para que o empreendimento da MOP iniciasse sua operação sem definição de um PBA indicando as medidas preventivas, mitigadoras e compensatórias aos impactos possíveis de ocorrer nas Terras Indígenas, contribuiu de forma determinante para o conflito socioambiental em análise.

O Estado do Pará, além de conceder as licenças sem o cumprimento integral das condicionantes, ainda ingressou com as Suspensões de Liminar $n^{\circ} 933$ e 1226, perante o STF com "o propósito exclusivo de garantir o funcionamento do empreendimento minerário, sem questionar a indenização estabelecida às aldeias indígenas" (STF. Suspensão de liminar $n^{\circ}$ 933, 2016), mesmo já tendo conhecimento de laudos médicos anexados ao Agravo de Instrumento interposto pelo MPF que demonstram:

(...) evidências de que a atividade de mineração tem causado graves danos às comunidades indígenas, tais como: (i) a contaminação das águas do Rio Cateté com metais pesados, o que afeta o principal recurso hídrico das aldeias; (ii) enfermidades ocasionadas pelo consumo de água contaminada (e.g.: angioedemas deformantes, lesões dermatológicas e cefaleias), doenças não registradas nas comunidades antes do inicio das atividades minerárias; e (iii) aumento anormal de 
casos de malformação e deficiências congênitas em recém-nascidos das aldeias indígenas. Ainda que esses indícios não sejam posteriormente confirmados no curso da ação civil pública, são suficientes para, com fundamento no princípio da precaução, justificar a suspensão da atividade minerária pelas instâncias ordinárias (BRASIL. SUPREMO TRIBUNAL FEDERAL. SUSPENSÃO DE LIMINAR 933, 2016).

Com isso, o Estado do Pará, em lugar de exercer sua autotutela e realizar a correção de seus atos, alinhou-se aos interesses da empresa, em detrimento dos interesses e defesa dos povos indígenas, de sua vida e saúde. Ademais ao não zelar pelo correto licenciamento ambiental termina por atuar como danos socioambientais e de violações de direitos humanos, em detrimento dos Princípios Orientadores.

\section{Uma oportunidade aplicação dos Princípios Orientadores sobre Empresas e Direitos Humanos na jurisprudência nacional}

Após a segunda grande guerra foi realizada a Conferência das Nações Unidas sobre Organizações Internacionais, na cidade de São Francisco, nos Estados Unidos. Nesta oportunidade foi assinado o documento denominado "Carta das Nações Unidas", que criou a ONU (PIOVESAN, 2015).

Nessa medida, em 1946, foi criada Comissão de Direitos Humanos, a qual foi extinta em 2006 e substituída pelo Conselho de Direitos Humanos (TERERZO, 2014)

Ainda sob a nomenclatura de Comissão, o Órgão de Direitos Humanos da ONU estabeleceu uma estrutura normativa para promover os direitos humanos. Esta estrutura, conhecida como "International Bill of Rigths (Carta Internacional de Direitos Humanos), é composta da Declaração Universal dos Direitos Humanos (DUDH), promulgada em 1948, e pela adoção, em 1976, de dois Pactos Internacionais de Direitos Humanos. O Pacto Internacional de Direitos Civis e Políticos (PIDCP) e o Pacto Internacional de Direitos Econômicos Sociais e Culturais (PIDESC) (WEIS, 2006).

Posteriormente, o sistema ONU de proteção dos Direitos Humanos passou a ser composto também pela Convenção Internacional sobre Eliminação de todas as formas de discriminação Racial e Convenção sobre os Direitos da Criança (RAMOS, 2015).

Nessa perspectiva, os Princípios Orientadores passaram a compor o sistema global de proteção dos direitos humanos da ONU, após serem aprovados por unanimidade, através da Resolução A/HRC/RES/17/4 (UNITED NATION - HUMAN RIGTHS). 
O embrião dos Princípios Orientadores surgiu ainda na década de 70, mesma década da descoberta da existência de minério nas Serras do Onça e do Puma. Nesse período, a ONU abriu sua agenda para a temática da relação entre as Empresas e a proteção e observância dos Direitos Humanos, mediante a aprovação, em 1974, da Resolução 1913, que criou a Comissão sobre Empresas Transnacionais (ARAGÃO, 2010).

A Comissão sobre Empresas Transnacionais apresentou, em 1990, a versão final da proposta de um Código de Conduta global, voltado para empresas transnacionais. Contudo, com a mudança do Secretário-Geral da ONU, em 1992, a proposta do Código de Conduta global foi abandonada (ARAGÃO, 2010).

Em razão da importância da discussão envolvendo empresas transnacionais e Direitos Humanos e de denúncias envolvendo violações a direitos humanos por transnacionais, a Comissão de Direitos Humanos da ONU, em 2003, firmou documento, por intermédio da Resolução 2003/16, que foi chamado de "Normas sobre Responsabilidades das Corporações Transnacionais e Outros Empreendimentos Privados com Relação aos Direitos Humanos" (Normas) (UNIVERSITY OF MINNESOTA).

Segundo Aragão, "sob a influência da Câmara internacional de Comércio e de outros coletivos empresariais" (ARAGÃO, 2010, p. 75), as Normas não foram aprovadas pela Comissão de Direitos Humanos, em 1994.

Diante da não aprovação das Normas, a Comissão de Direitos Humanos, por intermédio da Resolução 2005/69, requereu ao Secretário Geral da ONU a nomeação de um "Representante Especial do Secretário Geral para Direitos Humanos, Empresas Transnacionais e Outros Negócios", para implementar os objetivos propostos na mesma Resolução, a fim de dar continuidade na agenda da ONU em relação a temática empresas e Direitos Humanos (UNITED NATION - HUMAN RIGTHS).

Com isso, em 2008, foi apresentado, ao agora denominado Conselho de Direitos Humanos da ONU, Relatório sobre questões de direitos humanos e corporações transnacionais e outras empresas comerciais. Esse Relatório previa "uma estrutura conceitual e política para ancorar o debate sobre negócios e direitos humanos e ajudar a orientar todos os atores relevantes", como envolvendo governos, empresas, associações empresariais, sociedade civil, indivíduos e grupos afetados, investidores e outros ao redor do mundo (HUMAN RIGHTS COUNCIL, 2008).

O Relatório apresentado compreendia três pilares fundamentais, que "formam um todo complementar, na medida em que cada um apoia os outros na obtenção de um progresso sustentável” (HUMAN RIGHTS COUNCIL, 2008). 
O Relatório serviu de base para o chamado Princípios Orientadores, que foram aprovados, em 2011, por unanimidade, através da Resolução A/HRC/RES /17/4, pois foram mantidos os três pilares do documento apresentado em 2008, representados pelas palavras “proteger”, "respeitar” e remediar" (UNITED NATION - HUMAN RIGTHS).

Portanto, o documento aprovado pelo Conselho de Direitos Humanos em 2011 descreve um conjunto de recomendações para que Estados e empresas implementem uma política sustentada pelos pilares "Proteção, Respeito e Remediar" da ONU, a fim de gerenciar melhor os desafios das empresas e dos direitos humanos.

A ONU Brasil, ao comentar sobre cada um dos três pilares dos Princípios Orientadores, afirma que:

No âmbito do "Dever do Estado de Proteger", os princípios orientadores recomendam como os governos devem proporcionar maior clareza de expectativas e coerência de regras de negócio em relação aos direitos humanos. Os princípios da "Responsabilidade Corporativa de Respeitar" fornecem um modelo para as empresas de como saber e mostrar que estão respeitando os direitos humanos. Os princípios do "Acesso à Reparação" concentram-se na garantia de que, quando as pessoas forem prejudicadas por atividades empresariais, haja tanto a responsabilização efetiva e a reparação adequada, judicial e não judicial. (NAÇÕES UNIDAS BRASIL).

A organização não governamental Conectas Direitos Humanos, em material editado sobre a temática que comenta todos trinta e um artigos dispostos nos Princípios Orientadores, informa que: "Estes Princípios Orientadores se aplicam a todos os Estados e a todas as empresas, tanto transnacionais como de outro tipo, independentemente de sua dimensão, setor, localização, proprietários e estrutura" (CONECTAS DIREITOS HUMANOS).

Sheldon Leader, diretor do Essex Business and Human Rights Project (EBHR), em entrevista concedida a revista Sur, no ano de 2013, pouco depois do Primeiro Fórum Anual das Nações Unidas sobre Empresas e Direitos Humanos, realizado em Genebra, ressaltou que os Princípios Orientadores é uma afirmação clara que vai além do aumento dos tipos de responsabilidade que alguns tribunais vêm atribuindo a as empresas transnacionais.

Dessa forma, como se vê, além de a temática que envolve empresas e direitos humanos ser debatida em âmbito global desde antes do início do chamado Projeto Grande Carajás, que é um projeto de extração mineral iniciado na década de 1980, os Princípios Orientadores foram aprovados pela ONU, em 2011, ou seja, antes da distribuição da ACP proposta pelo MPF, que resultou no Caso objeto de análise nesta pesquisa. 
No âmbito regional de proteção dos direitos humanos, a Corte Interamericana de Direitos Humanos (Corte IDH), ao julgar o caso Povo Kalinã e Lokono x Suriname, em 25 de novembro de 2015, mencionou os Princípios Orientadores, ao condenar o Suriname, ressaltando na sentença que:

223. En este particular, el Tribunal toma nota de que las actividades mineras que generaron las afectaciones al medio ambiente y por ende a los derechos de los pueblos indígenas, fueron llevadas a cabo por actores privados, primero por la empresa Suralco y posteriormente por la joint venture denominada BHP Billiton-Suralco.

224. Al respecto, la Corte toma nota de los "Principios Rectores sobre las empresas y los derechos humanos", avalados por el Consejo de Derechos Humanos de la Naciones Unidas, mediante los cuales se ha establecido que las empresas deben actuar de conformidad con el respeto y la protección de los derechos humanos, así como prevenir, mitigar y hacerse responsables por las consecuencias negativas de sus actividades sobre los derechos humanos. En este sentido, tal como lo reiteran dichos principios, los Estados tienen la responsabilidad de proteger los derechos humanos de las personas contra las violaciones cometidas en su territorio y/o su jurisdicción por terceros, incluidas las empresas. Para tal efecto los Estados deben adoptar las medidas apropiadas para prevenir, investigar, castigar y reparar, mediante políticas adecuadas, los abusos que aquellas puedan cometer, actividades de reglamentación y sometimiento a la justicia .

225. En este sentido, el Representante Especial del Secretario General de Naciones Unidas para la cuestión de los derechos humanos y las empresas transnacionales y otras empresas, ha señalado que estas deberán respetar los derechos humanos de personas pertenecientes a grupos o poblaciones específicas, entre ellos los pueblos indígenas y tribales, y deberán prestarle especial atención cuando vulneren dichos derechos.

Moreira, ao analisar o caso Povo Kalinã e Lokono x Suriname, que envolve a concessão de exploração de bauxita pela empresa ALCOA, narra que, neste conflito, os planos de recuperação das áreas impactadas pela construção de uma grande estrada de acesso à mina e transporte de minério que criou obstruções ao uso e gozo do território tradicional do Povo Kalinã e Lokono em decorrência do ruído, vibrações e explosões de dinamite que, causaram ainda a perda da caça e pesca, além de contaminação do solo e das águas, o desfloramento de árvores frutíferas, estariam sendo efetivados com espécies inadequadas, ocasionando uma “transformação radical na paisagem” (2017, p. 205).

Portanto, como se vê, a Organização dos Estados Americanos (OEA), ao julgar conflito que, assim como o Caso MOP x Xikrins, envolve empreendimento minerário de 
empresa transnacional que resultou em dano socioambiental a indígenas não perdeu a oportunidade de se valer dos Princípios Orientadores, diferente do TRF $1^{\text {a }}$ e do STF, que no mesmo ano de 2015 proferiram decisões sobre o Caso objeto de análise deste estudo, mas não se valeram dos Princípios Orientadores.

Além do Caso Povo Kalinã e Lokono x Suriname, os próprios os documentos elaborados Grupo de Trabalho (GT) criado pelo Conselho de Direitos Humanos da ONU, que possui o objetivo de dar continuidade na temática ligada a empresas e Direitos Humanos, fazem prova de que o Caso MOP x Xikrin é uma oportunidade de introduzir a aplicação dos Princípios Orientadores na jurisprudência brasileira.

O GT, realizou visita ${ }^{4}$ oficial ao Brasil, entre os dias 7 e 16 de dezembro de 2015, ou seja, depois de TRF $1^{\text {a }}$ e STF proferirem as primeiras decisões sobre o Caso. No último dia da visita o GT apresentou uma Declaração com "Observações Preliminares" sobre diversos assuntos abordados durante o período da visita.

No primeiro tópico das "Observações Preliminares", chamado de "Observações Gerais", o GT afirmou que:

No que diz respeito ao nível de consciência sobre questões ligadas a empresas e direitos humanos, nossa impressão geral é que as principais empresas brasileiras, tanto privadas quanto públicas, e as associações empresariais em geral não conhecem os Princípios Orientadores das Nações Unidas. As empresas relatam ter recebido pouca orientação do Governo sobre as ações esperadas delas em relação aos Princípios Orientadores (ORAGANIZAÇÃO DAS NAÇÕES UNIDAS BRASIL).

No tópico "Plano de Ação", o GT, tendo em vista a promessa do Governo brasileiro de desenvolver um plano nacional de ação sobre empresas e direitos humanos, indica o seu modelo para orientação de desenvolvimento de planos de ação nacionais sobre empresas e direitos humanos, a fim de criar plataformas para diálogos envolvendo as várias partes interessadas, tais como: o Governo, as empresas e a sociedade civil (ORGANIZAÇÃO DAS NAÇÕES UNIDAS BRASIL).

Já Relatório Oficial final da visita do GT, que foi apresentado em junho de 2016, também antes do TRF e STF, ao tratar de projetos de desenvolvimento que envolvem mineração

\footnotetext{
${ }^{4}$ A visita do GT ocorreu seis semanas após o rompimento da barragem do Fundão, na Cidade de Mariana, no Estado de Minas Gerais, no dia 5 de novembro de 2015, construída pela empresa Samarco Mineração S.A, que é uma joint venture controlada pelas empresas Vale e BHP Billiton, rompeu, resultando no maior desastre socioambiental do País.
} 
e questões específicas envolvendo povos indígenas destacou que no Pará, assim como o caso concreto analisado na última sessão desta pesquisa, os projetos minerários de Belo Sun e de Grande Carajás ocasionaram agressões a direitos fundamentais dos povos indígenas (ORAGANIZAÇÃO DAS NAÇÕES UNIDAS BRASIL).

Ao tratar da consciência sobre negócios e direitos humanos no Brasil, o Relatório Oficial do GT, apesar de afirmar que medidas adotadas pelo Governo brasileiro, como o compromisso de aperfeiçoar as diretrizes da Organização para Cooperação e Desenvolvimento Econômico (OCDE), encorajam a aplicação dos pilares 1 e 2 dos Princípios Orientadores, reitera que "é necessária uma maior conscientização dos Princípios Orientadores e das questões comerciais e de direitos humanos, além de mecanismos de responsabilização para acompanhar o progresso na implementação dos compromissos assumidos" (ORAGANIZAÇÃO DAS NAÇÕES UNIDAS BRASIL).

Ao final do documento o GT faz vinte recomendações ao Brasil, dentre as quais, para alcançar os objetivos deste trabalho, destaca-se:

(a) Aumentar a conscientização e aumentar a capacidade dos funcionários públicos e legisladores quanto às respectivas obrigações e responsabilidades do governo e de todas as empresas comerciais, incluindo empresas estatais, para prevenir e tratar impactos adversos dos direitos humanos relacionados aos negócios, de acordo com os Princípios Orientadores sobre Empresas e Direitos Humanos; (b) Estabelecer expectativas claras nas políticas relevantes de que todas as empresas comerciais no Brasil respeitem os direitos humanos em todas as suas operações e realizem a devida diligência em direitos humanos em relação às suas operações nacionais e internacionais; (p) envidar seus melhores esforços para buscar o nível apropriado de recursos para permitir que os membros dos Ministérios Públicos Federais e Estaduais continuem a contestar as ações de empresas e órgãos públicos; (q) Analisar o uso atual do mecanismo legal de "suspensão de segurança", com o objetivo de garantir que não represente um obstáculo ao acesso à justiça para as comunidades afetadas por projetos de desenvolvimento em larga escala; $(\mathrm{u})$ Oferecer treinamento aprimorado em direitos humanos ao pessoal dos ministérios, funcionários responsáveis pelo licenciamento ambiental e juízes, a fim de garantir que os princípios legais atuais, os padrões de direitos humanos e as melhores práticas internacionais sejam conhecidos e aplicados pelo tomador de decisão (ORAGANIZAÇÃO DAS NAÇÕES UNIDAS BRASIL).

Com isso, fica claro que a visita do GT viabiliza ainda a utilização dos Princípios Orientadores no Caso em análise, desde o ano que TRF $1^{\text {a }}$ e STF passaram atuar, pois constatou que as empresa brasileiras não aplicam os Princípios Orientadores, assim como que atividade 
minerária desenvolvida por empresas transnacionais causam impactos ao modo de viver dos povos indígena (ORGANIZAÇÃO DAS NAÇÕES UNIDAS BRASIL).

É verdade que o STF se valeu do princípio da precaução ao julgar a suspensão de segurança $n^{\circ}$ 933, o que aproxima do uso do pilar "Remediar" dos Princípios Orientadores, o qual, de fato, compete ao Judiciário. Entretanto, perdeu a oportunidade de citar os Princípios Orientadores, como obstáculo argumentativo ao requerimento do Estado do Pará.

Sobretudo, como atualmente os Princípios Orientadores já são aplicáveis no Brasil e o caso concreto ainda não foi sentenciado no primeiro grau de jurisdição, o Judiciário brasileiro continua com a oportunidade de aplicar os Princípios Orientadores entre os fundamentos que sustentam a proteção dos direitos socioambientais e, assim, introduzir na jurisprudência pátria o mecanismos internacional de proteção de direitos humanos objeto de análise, a fim de para proteger de direitos socioambientais violados por empresas transnacionais.

\section{Conclusão}

A temática sobre Empresas e Direitos Humanos ainda é tema em formação do Direito Internacional, que demanda consolidação, inclusive por intermédio de normas de Hard Law, ainda mais considerando as extremidades que se encontram os atores diretamente ligados ao tema.

No entanto, no âmbito internacional, os Princípios Orientadores são uma realidade desde 2011, o que é suficiente para a aplicação deste documento no âmbito doméstico.

A aplicação doméstica dos Princípios Orientadores é ainda mais relevante quando se verifica a condição do Brasil de país com maior potencial de recurso naturais do mundo e, ao mesmo tempo, de país com significativa quantidade de povos e comunidades tradicionais diretamente vinculados à necessidade de proteção do meio ambiente.

Diante deste cenário embrionário dos Princípios Orientadores, pode se definir que a sociedade civil, as organizações não governamentais e os movimentos sociais, podem se articular a fim de cobrar que o documento internacional objeto deste estudo seja aplicado no Brasil, para que os órgãos responsáveis pelo processo de licenciamento ambiental e ao Poder Judiciário, se valendo de sua função típica, determinem a necessária observância dos Princípios Orientadores sobre empresas e Direitos Humanos para evitar a continuidade da habitual violação de direitos socioambientais por parte das empresas transnacionais instaladas no país.

\section{Referências}


ARAGÃO, Daniel Maurício Cavalcanti. Responsabilidade como Legitimação: capital transnacional e governança global na Organização das Nações Unidas. Tese (doutorado) Pontifícia Universidade Católica do Rio de Janeiro, Instituto de Relações Internacionais, 2010.

BRASIL. SUPREMO TRIBUNAL FEDERAL. Suspensão de liminar 933. Disponível em: www.stf.jus.br/portal/inteiroTeor/obterInteiroTeor.asp?idDocumento $=13375610$ Acesso em: 09 dez. 2020.

BRASIL. SUPREMO TRIBUNAL FEDERAL. Suspensão de liminar no 1226. Disponível em: http://portal.stf.jus.br/processos/downloadPeca.asp?id=15341114381\&ext=.pdf Acesso em 09 dez. 2020.

CONECTAS DIREITOS HUMANOS. Empresas e Direitos Humanos: Parâmetros da ONU para Proteger, Respeitar e Reparar. Disponível em: https://www.conectas.org/publicacoes/download/empresas-e-direitos-humanos-parametrosda-onu Acesso em: 09 dez. 2020

HUMAN RIGHTS COUNCIL. Promotion and protection of all human rights, civil, political, economic, social and cultural rights, including the right to development. Disponível em: https://business-humanrights.org/sites/default/files/reports-andmaterials/Ruggie-report-7-Apr-2008.pdf Acesso em 09 dez. 2020.

MINISTÉRIO PÚBLICO FEDERAL, 2020. MPF, Vale e indígenas Xikrin e Kayapó fazem acordo preliminar sobre Onça Puma. Disponível em: http://www.mpf.mp.br/pa/sala-deimprensa/noticias-pa/mpf-vale-e-indigenas-xikrin-e-kayapo-fazem-acordo-preliminar-sobreonca-puma Acesso em: 09 dez. 2020.

MOREIRA, Eliane Cristina Pinto. Justiça Socioambiental e Direitos Humanos: Uma análise a partir dos direitos territoriais de povos e comunidades tradicionais. $1^{\mathrm{a}}$ ed. Rio de Janeiro: Lumen Juris, 2017.

NAÇÕES UNIDAS BRASIL. Últimas notícias. Disponível em: https://nacoesunidas.org/conselho-de-direitos-humanos-aprova-principios-orientadores-paraempresas/ Acesso em: 09 dez. 2020.

ORGANIZAÇÃO DAS NAÇÕES UNIDAS BRASIL. Últimas notícias. Disponível em: https://nacoesunidas.org/brasil-desenvolvimento-economico-nao-deve-ocorrer-a-custa-dosdireitos-humanos-diz-grupo-de-especialistas-da-onu/ Acesso em: 27 dez. 2017.

ORGANIZAÇÃO DAS NAÇÕES UNIDAES BRASIL. Últimas notícias Disponível em: https://nacoesunidas.org/grupo-de-trabalho-da-onu-sobre-empresas-e-direitos-humanosdivulga-relatorio-sobre-o-brasil/ Acesso em: 27 dez. 2017.

PIOVESAN, Flavia. Direitos humanos e o direito constitucional internacional. $15^{\mathrm{a}}$ ed. São Paulo: Saraiva. 2015.

PROCESSO JUDICIAL ELETRÔNICO. MINISTÉRIO PÚBLICO FEDERAL. Ação Civil Pública n 0002383-85.2012.4.01.3905, de 02 de maio de 2011 [Inquérito Civil Público: ID. 
228588871] Disponível mediante login e senha em: https://pjelg.trfl.jus.br/pje/login.seam Acesso em: 09 dez. 2020.

PROCESSO JUDICIAL ELETRÔNICO. MINISTÉRIO PÚBLICO FEDERAL. Ação Civil Pública no 0002383-85.2012.4.01.3905, de 02 de maio de 2011 [Petição inicial: ID. 228588867] Disponível mediante login e senha em: https://pje1g.trf1.jus.br/pje/login.seam Acesso em: 09 dez. 2020.

PROCESSO JUDICIAL ELETRÔNICO. MINISTÉRIO PÚBLICO FEDERAL. Agravo de Instrumento $n^{0}$ 0042106-84.2015.4.01.0000, de 03 de agosto de 2015. Disponível mediante login e senha em: https://pje2g.trf1.jus.br/pje/login.seam Acesso em: 09 dez. 2020.

PROCESSO JUDICIAL ELETRÔNICO. MINISTÉRIO PÚBLICO FEDERAL. Ação Civil Pública no 0002383-85.2012.4.01.3905, de 02 de maio de 2011 [Relatório Final do Estudo Etnoecológico na Terra Indígena Xikrin do Cateté: ID. 228588872] Disponível mediante login e senha em: https://pjelg.trf1.jus.br/pje/login.seam Acesso em: 09 dez. 2020.

RAMOS, André de Carvalho. Teoria Geral dos Direitos Humanos na Ordem Internacional. $5^{\text {a }}$ ed. São Paulo: Saraiva, 2015.

SECRETARIA ESTADUAL DE MEIO AMBIENTE E SUSTENTABILDIADE. Relatório de Impacto Ambiental. Mineração Onça Puma. Disponível em: https://www.semas.pa.gov.br/documentos/relatorio-de-impacto-ambiental/ Acesso em: 09 dez 2020.

SUR - REVISTA INTERNACIONAL DE DIREITOS HUMANOS. Entrevista com Sheldon Leader Empresas Transnacionais e Direitos Humanos. Disponível em: http://sur.conectas.org/wp-content/uploads/2017/11/sur17-port-entrevista-sheldon-leader.pdf Acesso em: 09 dez. 2020.

TEREZO, Cristina Figueiredo. Sistema interamericano de direitos humanos: pela defesa dos direitos econômicos, sociais e culturais. Curitiba: Appris, 2014.

UNITED NATION - HUMAN RIGTHS. Special Representative of the Secretary-General on human rights and transnational corporations and other business enterprises. Disponível em: http://www.ohchr.org/EN/Issues/Business/Pages/SRSGTransCorpIndex.aspx Acesso em: 09 dez. 2020.

UNIVERSITY OF MINNESOTA. Responsibilities of transnational corporations and other business enterprises with regard to human rights. Disponível em: http://hrlibrary.umn.edu/links/res2003-16.html Acesso em 09 dez. 2020.

WEIS, Carlos. Os Diretos Humanos Contemporâneos. $1^{\mathrm{a}}$ ed, $2^{\mathrm{a}}$ tiragem. São Paulo: Malheiros. 2006, p. 68. ' 
